\title{
DEVELOPMENT AND VALIDATION OF RP-CHIRAL HPLC METHOD FOR QUANTIFICATION OF (S)-ISOMER IN TENOFOVIR DISOPROXIL FUMARATE
}

\author{
SURESH BABU BODEMPUDI ${ }^{1,2}$, RAVI CHANDRA BABU RUPAKULA ${ }^{1 *}$, KONDA S. REDDY ${ }^{3}$ \\ GITAM University, Visakhapatnam, India, and Dr. Konda's Life Sciences, Hyderabad \\ Email: b_sureshmsc2000@yahoo.co.in
}

Received: 21 Aug 2017, Revised and Accepted: 13 Oct 2017

\section{ABSTRACT}

Objective: The main objective of present study was to develop and validate a reverse phase enantioselective chiral high performance liquid chromatographic method was developed for enantiomeric resolution of Tenofovir disoproxil fumarate; it decreases the HIV infection in the human body. The method is specific, rapid, precise and accurate for the separation and determination of (S)-isomer in tenofovir disoproxil fumarate drug substance form.

Methods: The S-Isomer of Tenofovir disoproxil fumarate was resolved on a Chiral AGP (150 × 4.0 mm, $5 \mu \mathrm{m})$ column (L-41) using a mobile phase system containing $0.1 \mathrm{M}$ ammonium acetate in water $\mathrm{pH} 6.8$ with ammonia solution and methanol in the ratio of (85:15 v/v). The mobile phase was set at a flow rate of $0.8 \mathrm{ml} / \mathrm{min}$ and the volume injected was $10 \mu \mathrm{l}$ for every injection. The detection wavelength was set at $260 \mathrm{~nm}$ and the column temperature was set at $15^{\circ} \mathrm{C}$.

Results: The proposed method was productively applied for the quantitative determination of (S)-isomer in Tenofovir disoproxil fumarate drug substance form. The linear regression analysis data for calibration plots showed a good linear relationship over a concentration range of 0.125 to $3.75 \mu \mathrm{g} / \mathrm{ml}$ for (S)-isomer, $0.125-3.75 \mu \mathrm{g} / \mathrm{ml}$ for Tenofovir disoproxil fumarate. The mean values of the correlation coefficient were 0.999 and 0.999 for (S)-isomer and Tenofovir disoproxil fumarate. The method was validated as per the ICH guidelines. The detection limit (LOD) was about 0.05 $\mu \mathrm{g} / \mathrm{ml}$ and quantitation limit (LOQ) was about $0.125 \mu \mathrm{g} / \mathrm{ml}$ for (S)-isomer and Tenofovir disoproxil fumarate. The relative standard deviation was found to be $0.78 \%$ for $(\mathrm{S})$-isomer in Tenofovir disoproxil fumarate.

Conclusion: The developed and validated HPLC method and the statistical analysis showed that the method is repeatable and selective for the estimation of the (S)-isomer of the Tenofovir disoproxil fumarate drug substance.

Keywords: Tenofovir disoproxil fumarate, (S)-Isomer; RP-Chiral HPLC, Identification, Quantification and Validation

(C) 2017 The Authors. Published by Innovare Academic Sciences Pvt Ltd. This is an open-access article under the CC BY license (http://creativecommons.org/licenses/by/4.0/) DOI: http://dx.doi.org/10.22159/ijcpr.2017v9i6.23425

\section{INTRODUCTION}

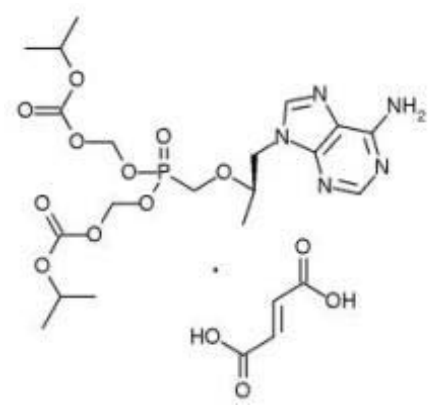

Fig. 1: Chemical structure of tenofovir disoproxil fumarate

Tenofovir disoproxil fumarate (TDF) is a fumaric acid, salt of bis-isopropoxycarbonyloxy methyl ester derivative of tenofovir. Chemically it is 9-[(R)-2-[[bis [[isopropoxy-carbonyl) oxy] methyl] phosphinyl] methoxy] propyl] adenine fumarate [1-2]. TDF is the first nucleotide analog approved for HIV-1 treatment. Tenofovir is a nucleotide reverse transcriptase inhibitor [3] used in combination with other antiretrovirals for the treatment of HIV infections. TDF remains in cells for longer periods of time than many other antiretroviral drugs, thereby allowing for once-daily dosing. Literature survey reveals that there are several reports describing the determination of Tenofovir in plasma using HPLC coupled with fluorescence and UV detection [4-8]. Liquid chromatography coupled with tandem mass spectrometry was also reported [9-11]. Spectrophotometric [12]. The focus of the present study is to develop and validate a rapid, stable, and economic high performance liquid chromatographic method for quality control of TDF in drug substance form. So it is essential to find an effective way to analyze the $(S)$ enantiomer of Tenofovir disoproxil fumarate, the chemical structures of Tenofovir disoproxil fumarate and (S)-enantiomer are shown in fig. 1 and in fig. 2 The developed chiral RP-HPLC method was reproducible and accurate for the quantitative determination of (S)-enantiomer in Tenofovir disoproxil fumarate The newly developed method was validated as per ICH guidelines [13-16].

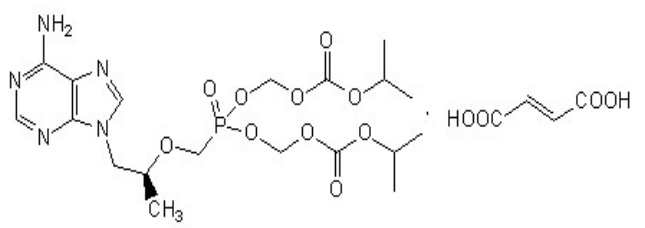

Fig. 2: Chemical structure of tenofovir disoproxil fumarate (S) enantiomer

\section{MATERIALS AND METHODS}

Instruments

Chromatography was carried out by using Water's Alliance instrument equipped with column oven, UV detector, and the data was processed using a computer program (with Empower-2 software). 


\section{Chemicals and reagents}

Tenofovir disoproxil fumarate racemic mixture $( \pm)$ was obtained from the R\&D department of Dr. Konda's life sciences (Hyderabad, India). Merck grade Ammonium acetate, Ammonia, and methanol were purchased from Merck (Mumbai, India). A stock solution of analyte was prepared in the diluent at a concentration of $0.1 \mathrm{mg} / \mathrm{ml}$. Tenofovir disoproxil fumarate with $99.40 \%$ purity and (S)-isomer (the undesired isomer (with $99.02 \%$ purity) were prepared in the laboratory by using preparative HPLC.

\section{Chromatographic conditions}

The chromatographic conditions were optimized using a chiral RP stationary phase, Chiral AGP column $(150 \times 4.0 \mathrm{~mm}, 5 \mu \mathrm{m}$, Supelco brand (a member of Sigma-Aldrich group). The isocratic mobile phase composition was a mixture of $0.1 \mathrm{M}$ ammonium acetate in water $\mathrm{pH} 6.8$ with ammonia solution and methanol $(85: 15 \mathrm{v} / \mathrm{v})$, which was pumped at a flow rate of $0.8 \mathrm{ml} / \mathrm{min}$. The temperature of the column was maintained at $15^{\circ} \mathrm{C}$ and the eluent was monitored at a wavelength of $260 \mathrm{~nm}$. The injection volume was $10 \mu \mathrm{l}$.

The chromatographic parameters, including the retention factor $(\mathrm{k})$, the separation factor $(\alpha)$, and the resolution (Rs) were selected to evaluate the separation of compounds. All the chromatographic results were repeated three times.

\section{Sample preparation}

Racemic mixture solution of Tenofovir disoproxil fumarate and (S)enantiomer $(100 \mu \mathrm{g} / \mathrm{ml}$ each) prepared in mobile phase was used in the method development.

Stock solutions of Tenofovir disoproxil fumarate $(0.1 \mathrm{mg} / \mathrm{ml})$ and (S)-enantiomer $(0.1 \mathrm{mg} / \mathrm{ml})$ were prepared by dissolving an appropriate amount of the substance in the mobile phase. The analyte concentration of Tenofovir disoproxil fumarate was fixed as $250 \mu \mathrm{g} / \mathrm{ml}$. Tenofovir disoproxil fumarate solutions spiked with low levels of (S)-enantiomer were prepared by transferring calculated amount of undesired enantiomer stock solution with a pipette into the calculated amount of Tenofovir disoproxil fumarate stock solution, and then the solution was added to volume with mobile phase and mixed well.

\section{Validation of the method}

The specificity of the method is performed by injecting both isomers and racemic mixture individually. The specificity determined by using peak purity, resolution.

The system suitability of the method performed by adding known concentration $(2.5 \mu \mathrm{g} / \mathrm{ml})$ of undesired isomer to Tenofovir disoproxil fumarate. The system suitability is confirmed by using resolution, tailing factor, Tangent.

Method reproducibility was determined by measuring repeatability and intermediate precision of retention times and peak areas for each enantiomer. The repeatability of the method was determined by analyzing six replicate injections containing Tenofovir disoproxil fumarate $(250 \mu \mathrm{g} / \mathrm{ml})$ spiked with (S)-enantiomer $(1.0 \%, 2.5$ $\mu \mathrm{g} / \mathrm{ml})$. The intermediate precision was determined over $2 \mathrm{~d}$ by performing six successive injections $(n=6)$ each day and also performed intermediate precision with different system, different analyst and with a different column by using six injections $(n=6)$.

The limit of detection (LOD) and limit of Quantitation (LOQ) for (S)enantiomer was achieved by injecting a series of dilute solutions of by using standard deviation slope method (ICH Q2 (R1)). The LOQ level precision of the developed chiral method for (S)-enantiomer was checked by analyzing six solutions of (S)-enantiomer prepared at LOQ level and calculating the percentage relative standard deviation of the area.

Detector response linearity was assessed by preparing eight calibration sample solutions of (S)-enantiomer co-vering from 0.5 $\mu \mathrm{g} / \mathrm{ml}(\mathrm{LOQ})$ to $3.75 \mu \mathrm{g} / \mathrm{ml}(0.125,0.50,1.00,1.50,2.00,2.50,3.00$ and $3.75 \mu \mathrm{g} / \mathrm{ml}$ ) in mobile phase. The regression curve was obtained by plotting peak area versus concentrations, using the least square method. The percentage relative standard deviation of the slope and $y$-intercept of the calibration curve was calculated.

The accuracy of the method was carried out by injecting a known concentration of (S)-enantiomer to the Tenofovir disoproxil fumarate. The accuracy was calculated in terms of recovery (\%). The study was carried out in triplicate at covering from LOQ, to 3.75 $\mu \mathrm{g} / \mathrm{ml}$ (LOQ, 1.25, 2.50 and $3.75 \mu \mathrm{g} / \mathrm{ml}$ ) in the mobile phase. The recovery of (S)-enantiomer was calculated.

To determine the robustness of the method, the flow rate was changed at the pace of 0.2 units from 0.6 to $1.0 \mathrm{ml} / \mathrm{min}$. The effect of a change in the percent Buffer and Methanol $( \pm 10 \%)$, and column temperature at $10^{\circ} \mathrm{C}$ and $20^{\circ} \mathrm{C}$ instead of $15^{\circ} \mathrm{C}$ were studied, and the other chromatographic conditions were held constant as stated previously.

The solution stability of Tenofovir disoproxil fumarate at analyte concentration was studied by keeping the solution in a tightly capped volumetric flask at room temperature on a laboratory bench for $48 \mathrm{~h}$. The content of (S)-enantiomer was checked at $6 \mathrm{~h}$ interval up to the study period. Mobile phase stability was carried out by evaluating the content of (S)-enantiomer in Tenofovir disoproxil fumarate sample solutions prepared freshly at $6 \mathrm{~h}$ interval of $48 \mathrm{~h}$. The same mobile phase was used during the study period.

\section{RESULTS AND DISCUSSION}

\section{Optimization of chromatographic conditions}

To develop a rugged and suitable reverse phase HPLC method for the separation of the two enantiomers, different stationary phases and mobile phases were employed. Chiralpak AGP column $(150 \times$ $4.0 \mathrm{~mm}, 5 \mu \mathrm{m}$ ) with a mobile phase consisting of $0.1 \mathrm{M}$ ammonium acetate in water $\mathrm{pH} 6.8$ with ammonia solution and methanol $(85: 15 \mathrm{v} / \mathrm{v})$ was used. It was continued to select the best stationary and mobile phases that would give optimum resolution and selectivity for the two enantiomers. There was an indication of separation on Chiralpak AGP $(150 \times 4.0 \mathrm{~mm}, 5 \mu \mathrm{m})$ column using a mobile phase consisting of $0.1 \mathrm{M}$ ammonium acetate in water $\mathrm{pH}$ 6.8 with ammonia solution and methanol $(85: 15 \mathrm{v} / \mathrm{v})$. The composition of the mobile phase was optimized to enhance the chromatographic efficiency and resolution between the enantiomers. Based on the data obtained from the method development and optimization activities, Chiralpak AGP (150 × 4.0 $\mathrm{mm}, 5 \mu \mathrm{m}$ ) column with a mobile phase of $0.1 \mathrm{M}$ ammonium acetate in water $\mathrm{pH} 6.8$ with ammonia solution and methanol $(85: 15 \mathrm{v} / \mathrm{v})$ was selected from the method development. The flow rate of the final method was $0.8 \mathrm{ml} / \mathrm{min}$ with injection volume 10 $\mu \mathrm{l}$. The column temperature wias alnsd the detection wavelength was $260 \mathrm{~nm}$. Under these conditions, the two enantiomers were separated well and the peak of (S)-enantiomer eluted after the main peak of Tenofovir disoproxil fumarate. In the optimized method, the typical retention time of Tenofovir disoproxil fumarate and (S)-enantiomer were 7.4 and $10.6 \mathrm{~min}$ respectively. Baseline separation of Tenofovir disoproxil fumarate and (S)-enantiomer was obtained with total run time of $20 \mathrm{~min}$. The final optimized method was productively applied to separate (S)-isomer from Tenofovir disoproxil fumarate and was proven to be reproducible and accurate for the quantitative determination of (S)-isomer in Tenofovir disoproxil fumarate drug substance form. This is the first method to estimate (S) enantiomer in Tenofovir disoproxil fumarate drug substance form. The separation of an approximately $1: 1(\mathrm{wt} / \mathrm{wt}$ ) mixture solution (in diluent) of the two enantiomers shown in fig. 3. HPLC chromatogram of Tenofovir disoproxil fumarate bulk drug sample $(0.1 \mathrm{mg} / \mathrm{ml})$ shown in fig. 4 and HPLC chromatogram of (S) enantiomer $(0.1 \mathrm{mg} / \mathrm{ml})$ was shown in fig. 5. 


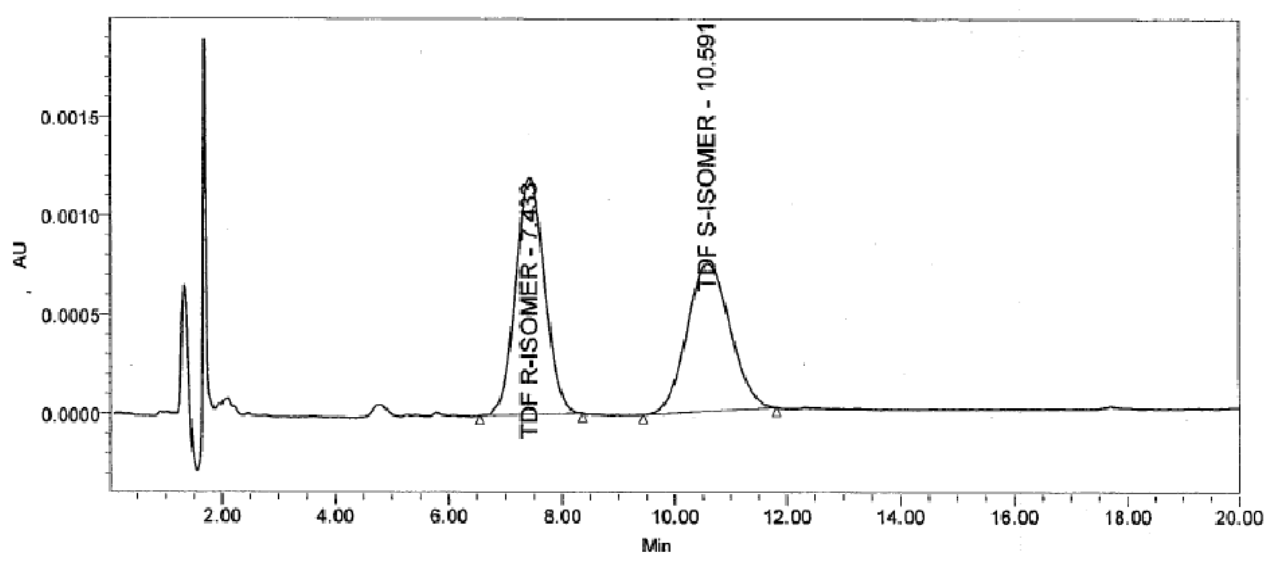

Fig. 3: Tenofovir disoproxil fumarate and (S) enantiomer

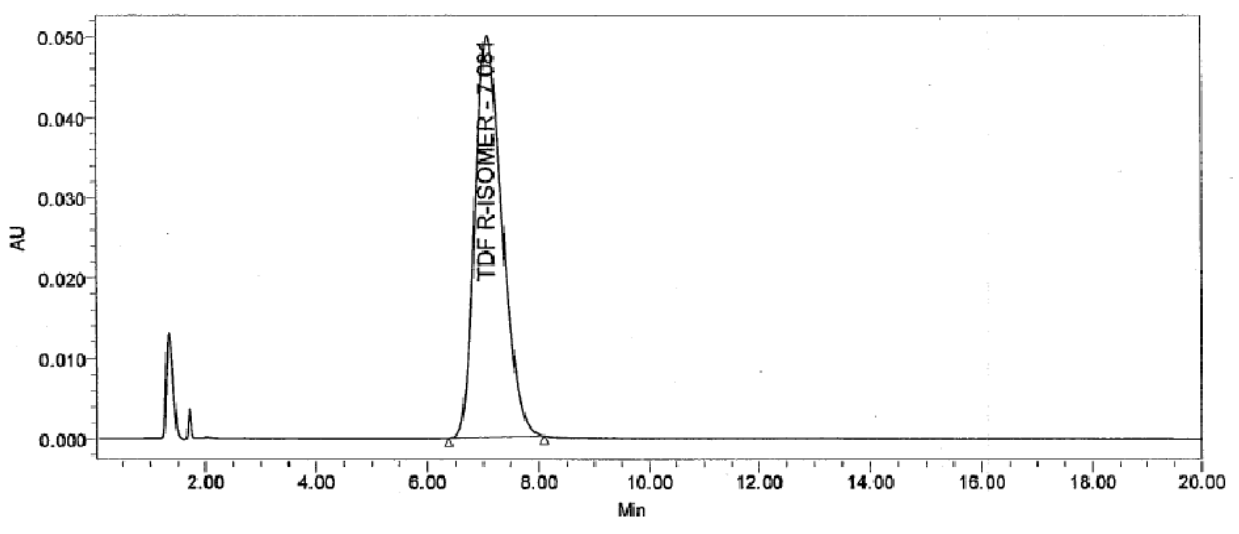

Fig. 4: Tenofovir disoproxil fumarate $0.1 \mathrm{mg} / \mathrm{ml}$ solution

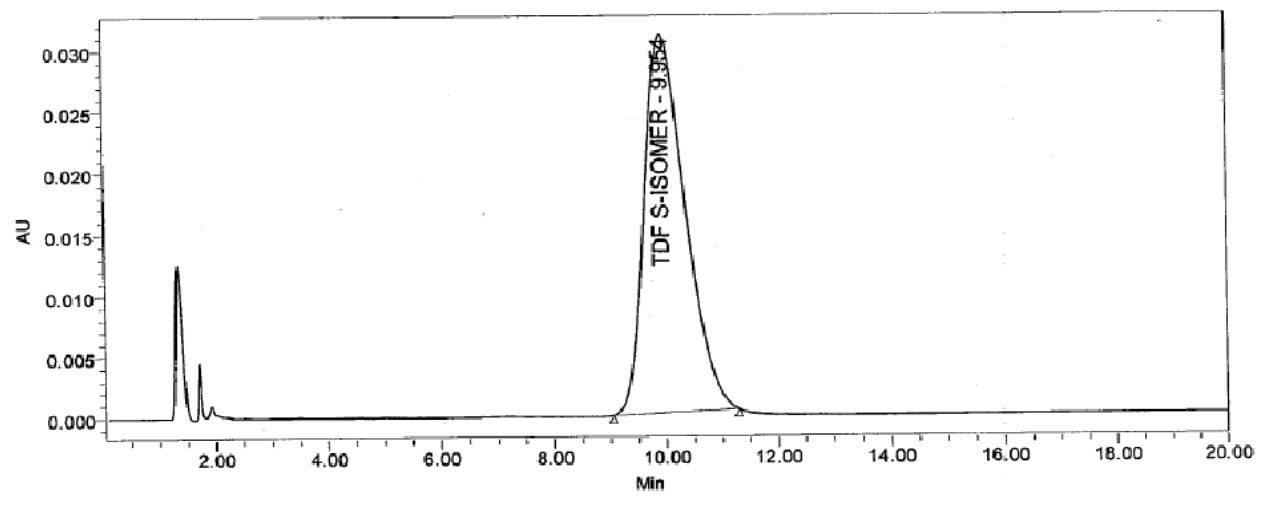

Fig. 5: (S) Isomer $0.1 \mathrm{mg} / \mathrm{ml}$ solution

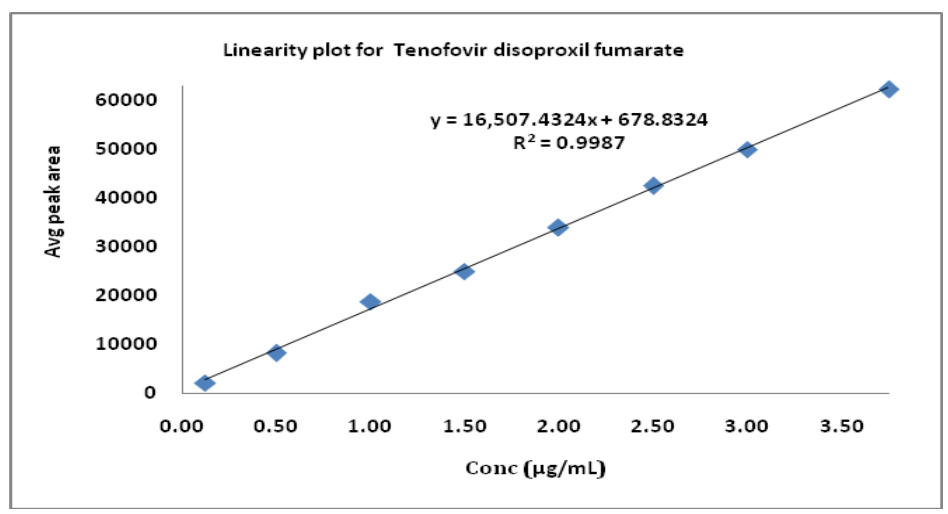

Fig. 6: Linearity plot for tenofovir disopropoxil fumarate 


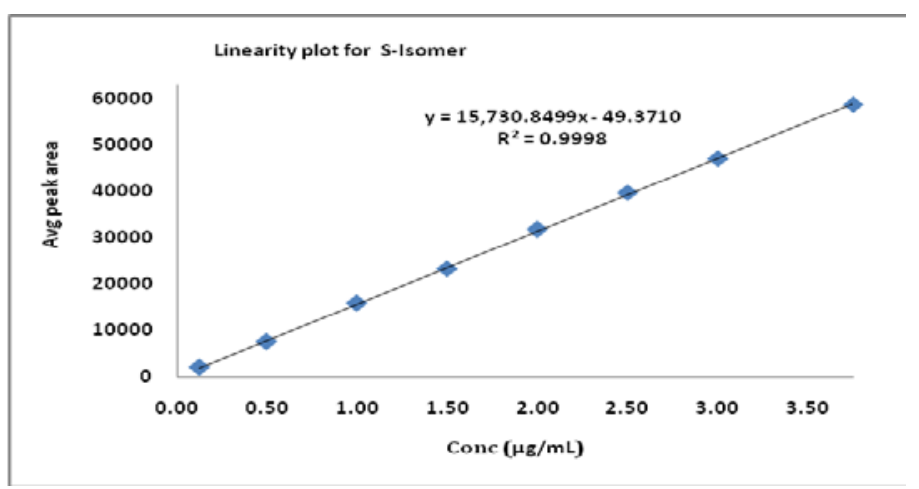

Fig. 7: Linearity plot for S-Isomer

\section{Validation results of the method}

The HPLC condition of the final method was evaluated for its specificity, LOD, LOQ, linearity, accuracy, precision, robustness and stability. The specificity of the method was determined by using peak purity. The specificity results are given in table 1 .

Table 1: Specificity

\begin{tabular}{lll}
\hline Compound & Purity angle & Purity threshold \\
\hline S-Isomer & 0.921 & 2.324 \\
Tenofovir disoproxil fumarate & 3.567 & 4.291 \\
\hline
\end{tabular}

The limit of detection and limit of quantification of (S)-isomer was found to be $0.05 \mu \mathrm{g} / \mathrm{ml}$ and $0.125 \mu \mathrm{g} / \mathrm{ml}$, respectively. Calculated the LOD and LOQ by using standard and slope method. The LOD and LOQ values for Tenofovir disoproxil fumarate were $0.05 \mu \mathrm{g}$ and $0.125 \mu \mathrm{g}$. Method precision for (S)-enantiomer at $0.125 \mu \mathrm{g}$ was less than $2.0 \%$ RSD. The resolutions between the two isomers were found more than 2.0. Therefore, this method had adequate sensitivity for the detection and estimation of $(\mathrm{S})$-enantiomer in Tenofovir disoproxil fumarate.
Good linearity of (S)-enantiomer was evaluated over eight levels of (S)-enantiomer solutions from $0.125 \mu \mathrm{g} / \mathrm{ml}$ to $3.75 \mu \mathrm{g} / \mathrm{ml}$, with the linear regression equation $\mathrm{y}=\mathrm{mx}+\mathrm{c}$, where $\mathrm{x}$ is the concentration in $\mu \mathrm{g} / \mathrm{ml}$, and $\mathrm{y}$ is the corresponding peak area of undesired enantiomer in $\mathrm{mV} / \mathrm{s}$. We observed linear results with respect to concentration for (S)-enantiomer. The correlation coefficient value is more than 0.999 . The linearity results of Tenofovir disoproxil fumarate and (S) enantiomer are given in table 2 and in table 3 . The linearity graph was shown in fig. 6 and in fig. 7 correspondingly.

Table 2: Linearity of tenofovir disopropoxil fumarate

\begin{tabular}{lll}
\hline S. No. & Concentration $(\boldsymbol{\mu g} / \mathbf{m l})$ & R-Isomer peak $* \mathbf{n}=\mathbf{8})$ \\
\hline 1 & 0.125 & 2174 \\
2 & 0.50 & 8270 \\
3 & 1.00 & 18759 \\
4 & 1.50 & 25005 \\
5 & 2.00 & 33936 \\
6 & 2.50 & 42456 \\
7 & 3.00 & 49944 \\
8 & 3.75 & 62181 \\
Correlation coefficient & & 0.9993 \\
Slope & & 16507.4324 \\
Y-intercept & & 678.8324 \\
$\mathrm{r}^{2}$ & & 0.9987 \\
\hline
\end{tabular}

\footnotetext{
* Mean of eight determinations
}

Table 3: Linearity of (S)-isomer

\begin{tabular}{lll}
\hline S. No & Concentration $(\boldsymbol{\mu g} / \mathbf{m l})$ & S-Isomer peak $* \mathbf{n}=\mathbf{8})$ \\
\hline 1 & 0.125 & 1994 \\
2 & 0.50 & 7502 \\
3 & 1.00 & 15795 \\
4 & 1.50 & 23311 \\
5 & 2.00 & 31750 \\
6 & 2.50 & 39656 \\
7 & 3.00 & 47005 \\
8 & 3.75 & 58723 \\
Correlation coefficient & & 0.9999 \\
Slope & & 15730.8499 \\
Y-intercept & & -49.3710 \\
$r^{2}$ & & 0.9998 \\
\hline
\end{tabular}

* Mean of eight determinations 
The standard addition and recovery experiments were conducted for (S)-enantiomer in bulk samples in triplicate at $0.125 \mu \mathrm{g} / \mathrm{ml}$ to $3.75 \mu \mathrm{g} / \mathrm{ml}(0.125,0.5,1.0,1.5,2.0,2.5,3.0$ and $3.75 \mu \mathrm{g} / \mathrm{ml})$. The accuracy was in terms of recovery (\%). The recovery was calculated by back-calculated concentration at each level in each preparation. The recovery is not less than $99.2 \%$ and not more than $102.8 \%$. The recovery results are given in table 4 .

Table 4: Accuracy

\begin{tabular}{lll}
\hline Added amount $(\boldsymbol{\mu g})$ & Recovery (\%) & *\%RSD (n = 3) \\
\hline 1.5 & 99.33 & 1.01 \\
3 & 101.67 & 0.76 \\
4.5 & 102.00 & 0.33 \\
7.5 & 101.87 & 0.26 \\
9 & 100.33 & 0.68 \\
10.5 & 99.24 & 1.13 \\
12 & 100.75 & 0.25 \\
\hline
\end{tabular}

* Mean of three determinations

The repeatability and intermediate precision were expressed as relative standard deviation (RSD). For this study, a solution of Tenofovir disoproxil fumarate $(250 \mu \mathrm{g} / \mathrm{ml})$ spiked with (S)enantiomer $(1.0 \%, 2.5 \mu \mathrm{g} / \mathrm{ml})$ was analyzed in six injections to establish repeatability. RSD values were better than $0.5 \%$ for the retention times of both the enantiomers. In the intermediate precision study results shown that RSD values were in same order of magnitude than those obtained for repeatability studies were captured in table 5 . All these values indicated that the method was precise.

Table 5: Ruggedness

\begin{tabular}{ll}
\hline Name of the Interval & $*$ \%RSD (n = 6) \\
\hline Day-1 & 0.3 \\
Day-2 & 0.4 \\
Day-3 & 0.5 \\
Diff system & 0.7 \\
Diff column & 0.6 \\
Diff analyst & 0.2 \\
\hline
\end{tabular}

* Mean of six determinations

As per ICH, the method robustness studies were demonstrated by adjusting flow rate, column temperature and mobile phase composition variations. The chromatographic resolution of
Tenofovir disoproxil fumarate and (S)-enantiomer was more than 2.0 under all separation conditions. The robustness results were captured in table 6.

Table 6: Robustness

\begin{tabular}{llll}
\hline Description & USP tailing & USP & USP \\
\cline { 2 - 4 } & & Tangent & 3829 \\
Resolution & 2.5 \\
Column flow: $0.80 \mathrm{ml} / \mathrm{min}$ & 1.0 & 4362 & 2.2 \\
Column flow: $1.20 \mathrm{ml} / \mathrm{min}$ & 1.0 & 4125 & 3829 \\
Column Temp: $25^{\circ} \mathrm{C}$ & 1.1 & 3242 & 2.3 \\
Organic ratio: $110 \%$ & 1.0 & 2.3 & 2.1 \\
Organic ratio: $90 \%$ & 1.0 & 2.3 & \\
\hline
\end{tabular}

The stability of the solution and mobile phase used in this method was tested over a long time. No significance change in (S)-enantiomer content was observed in Tenofovir disoproxil fumarate sample during solution stability and mobile phase stability experiments, and the RSD values were less than $2.0 \%$ for (S)-enantiomer peak area. No unknown peak was observed in above stability conditions. Hence, the Tenofovir disoproxil fumarate sample solution and the mobile phase were stable for up to $48 \mathrm{~h}$ and the results were captured in table 7.

Table 7: Solution stability

\begin{tabular}{llll}
\hline S. No & Time interval & R-isomer peak *area (n=7) & S-isomer peak *area (n=7) \\
\hline 1 & Initial & 18752 & 15782 \\
2 & After 6 H & 18648 & 15691 \\
3 & After 12 H & 18729 & 15942 \\
4 & After 18 H & 18658 & 15858 \\
5 & After 24 H & 19022 & 15642 \\
6 & After 36 H & 18926 & 16001 \\
7 & After 48 H & 18451 & 15978 \\
Average & & 18741 & 15842 \\
STDEV & & 188.4537 & 141.6769 \\
\% RSD & & 1.01 & 0.89 \\
\hline
\end{tabular}

* Mean of seven determinations 


\section{Batch analysis}

By using this method we can analyze and quantify (S)-isomer in
Tenofovir disoproxil fumarate in manufacturing batches and R and D samples. We get repeatable results in all samples at Quality control department and captured in table 8.

Table 8: Batch analysis

\begin{tabular}{llll}
\hline S. No & Batch No & S-isomer content * $\mathbf{\%} \mathbf{w} / \mathbf{w})$ & Average $*$ (\% w/w) \\
\hline 1 & PT001 Pre-01 & 0.12 & 0.13 \\
2 & PT001 Pre-02 & 0.14 & 0.14 \\
3 & PT002 Pre-01 & 0.15 & 0.07 \\
4 & PT002 Pre-02 & 0.13 & \\
5 & RD001 Pre-01 & 0.08 & 0.08 \\
6 & RD001 Pre-02 & 0.06 & \\
7 & RD002 Pre-01 & 0.07 & \\
8 & RD002 Pre-02 & 0.09 & \\
\hline
\end{tabular}

* Mean of two determinations

\section{CONCLUSION}

A simple, specific, linear, accurate and precise reverse phase chiral HPLC method was successfully developed, which was capable of separating the undesired enantiomer from Tenofovir disoproxil fumarate. $\alpha 1$-acid glycoprotein chiral Chiralpak AGP (L-41) column was found to be selective for the enantiomers of Tenofovir disoproxil fumarate. The developed and validated method can be used for the chiral purity testing of Tenofovir disoproxil fumarate. The developed method is also stable and can be used for the quantitative determination of chiral impurity in Tenofovir disoproxil fumarate drug substance form.

\section{ACKNOWLEDGEMENT}

The authors wish to state their thanks to the organization of Dr. Konda's life sciences, Hyderabad, India for providing the samples, Brundavan laboratories private limited, Hyderabad, India for providing the research facilities and Gitam University, Visakhapatnam, India for providing the technical support.

\section{CONFLICT OF INTERESTS}

Declared none

\section{REFERENCES}

1. Neil MJO. Ed. by the Merck Index-An Encyclopedia of Chemicals, Drugs and Biological; Merck and Co. Inc; 2006.

2. Sweetman SC. Ed. by Martindale, the Complete Drug Reference; Pharmaceutical Press; 2007.

3. Keamey BP, Flherty JF, Shah J. Tenofovir disoproxil fumarate: clinical pharmacology and pharmacokinetics. Clin Pharmacokinet 2004;43:595-612.

4. Seshachalam U, Rajababu B, Haribabu B, Chandrasekhar KB. Enantiomeric separation of tenofovir on an achiral C18 column by HPLC using L-phenylalanine as a chiral mobile phase additive. J Liq Chromatogr Relat Technol 2008;31:410-20.

5. Kandagal PB, Manjunatha DH, Seetharamappa J, Kalanur SS. RPHPLC method for the determination of tenofovir in pharmaceutical formulations and spiked human plasma. Anal Lett 2008;41:561-70.
6. Sentenac S, Fernandez C, Thuillier A, Lechat P, Aymard G. Sensitive determination of TNF in human plasma samples using reversed-phase liquid chromatography. J Chromatography B 2003;793:317-24.

7. Jullien V, Treluyer JM, Pons G, Rey E. Determination of TNF in human plasma by high-performance liquid chromatography with spectrofluorimetric detection. J Chromatography B 2003;785:377-81.

8. Sparidens RW, Crommentuyon KM, Scheelens JH, Beijnen JH. Liquid chromatographic assay for the antiviral nucleotide analogue TNF in plasma using derivatization with chloroacetaldehyde. J Chromatography 2003;791:227-33.

9. Delahunty T, Bushman L, Fletcher CV. Sensitive assay for determining plasma TNF concentrations by LC/MS/MS. J Chromatogr B: Anal Technol Biomed Life Sci 2006;830:6-12.

10. Massaki T, Yuichi K, Naoya O, Atsushi H, Kazuhide B, Tsuguhiru K. Determination of plasma tenofovir concentrations using a conventional LC-MS method. Biol Pharm Bull 2007;30:1784-6.

11. Bezy V, Morin P, Couerbe P, Lepen G, Agrofoglio L. Simultaneous analysis of several antiretroviral nucleosides in rat-plasma by high-performance liquid chromatography with UV using acetic acid/hydroxylamine buffer Test of this new volatile medium-pH for HPLC-ESI-MS/MS. J Chromatogr B: Anal Technol Biomed Life Sci 2005;821:132-43.

12. Shirkhedkar AA, Bhirud $\mathrm{CH}$, Surana SJ. Application of UVspectrophotometric methods for estimation of tenofovir disoproxil fumarate in tablets. Pakistan J Pharm Sci 2009; 22:27-9.

13. ICH. Q2 (R1) Validation of Analytical Procedures: Text and Methodology. International Conference on Harmonization of Technical Requirements for Registration of Pharmaceuticals for Human Use, ICH harmonized Tripartite Guideline; 2005.

14. Kanarek AD. Analytical methods: a statistical perspective on ICH Q2A and Q2B guidelines for validation of analytical methods. BioPharm Int 2005;19:28-33.

15. ICH guidance on method validation; validation of analytical procedures Text and Methodology Q2 (R1); 2005

16. ICH harmonized tripartite guideline impurities in new drug substances Q3 A (R2); 2006. 